\title{
Role of the Site of Protonation in the \\ Low-Energy Decompositions of Gas-Phase Peptide Ions
}

\author{
Kathleen A. Cox* and Simon J. Gaskell \\ Michael Barber Centre for Mass Spectrometry, Department of Chemistry, UMIST, Manchester, United Kingdom
}

Michael Morris

VG Organic, Altrincham, Cheshire, United Kingdom

Andrew Whiting

Department of Chemistry, UMIST, Manchester, United Kingdom

\begin{abstract}
The dissociation of singly or multiply protonated peptide ions by using low-energy collisional activation (CA) is highly dependent on the sites of protonation. The presence of strongly basic amino acid residues in the peptide primary structure dictates the sites of protonation, which generates a precursor ion population that is largely homogeneous with respect to charge sites. Attempts to dissociate this type of precursor ion population by low-energy $\mathrm{CA}$ result in poor fragmentation via few pathways. The work described here represents a systematic investigation of the effects of charge heterogeneity in the precursor ion population of a series of model peptides in low-energy CA experiments. Incorporation of acidic residues in the peptide RLC $^{*}$ IFSC*FR (where $C^{*}$ indicates a cysteic acid residue), for example, balances the charge on the basic arginine residues, which enables the ionizing protons to reside on a number of less basic sites along the peptide backbone. This results in a precursor ion population that is heterogeneous with respect to charge site. Low-energy CA of these ions results in diverse and efficient fragmentation. Molecular modeling has been utilized to demonstrate that energetically preferred conformations incorporate an intraionic interaction between arginine and cysteic acid residues. ( $/$ Am Soc Mass Spectrom 1996, 7, 522-531)
\end{abstract}

$\mathrm{T}$ Tandem mass spectrometry has assumed increasing importance in recent years as an analytical tool for the characterization of peptides. Mechanisms have been elucidated for the formation of sequence-specific fragment ions due to cleavage along the peptide backbone with charge retention on the $\mathrm{N}$ or C-terminal fragment, in addition to residue specific side-chain cleavages [1-3]. Recent reports also have proposed mechanisms for the formation of fragment ions from multiply charged precursor ions $[4,5]$. Nevertheless, the prediction of fragmentation processes of peptide ions remains complex.

Several studies that involved both high- [6] and low-energy $[7,8]$ collision-activated decomposition (CAD) have shown that the nature of product ions derived from the dissociation of a precursor peptide ion is highly dependent on the primary structure of the

Address reprint requests to Simon J. Gaskell, Michael Barber Centre for Mass Spectrometry, Department of Chemistry, UMIST, P.O. Box 88, Manchester M60 1QD, United Kingdom.

*Present address: Department of Drug MetabolisIu, ScheringPlough Research Institute, Kenilworth, NJ 07033-0539. peptide, particularly on the number and location of the basic amino acid residues. In the presence of a highly basic amino acid residue in the primary peptide sequence, a precursor ion population is generated in which the ionizing proton is expected to be localized on this residue in a high proportion of the ions. In high-energy $\mathrm{CAD}$, these precursor ions may fragment via "charge-remote" processes [9] in which ions are formed that contain the charge on this basic site. A strongly localized charge stabilizes the precursor ion and may facilitate the charge-remote decomposition mechanism [10]. Thus, precharged derivatives have been incorporated into peptide structures to control the fragmentation processes [11-13].

Low-energy $(<300 \mathrm{eV}$ in the laboratory frame of reference) $\mathrm{CAD}$ of peptide ions is generally achieved by multiple collisions of low-energy precursor ions with a neutral target gas, which thereby achieves a stepwise energy deposition in the precursor ions. The lifetime of the precursor ion-target complex and the time available for subsequent decomposition are significantly longer than in the case of the high-energy 
dissociation experiments (and the multiplicity of collisions is generally greater). As a result, there is a prevalence of fragmentation mechanisms (such as rearrangements $[5,14,15]$ and some multistage processes [16]) that have low internal energy thresholds or require longer reaction times.

The increasing availability and application of lowenergy tandem mass spectrometers such as triple quadrupole and ion trapping instruments have provided the incentive for improved understanding of the low-energy CAD of peptide ions. The poor fragmentation efficiencies observed in the low-energy $\mathrm{CAD}$ of singly protonated peptides that contain strongly basic residues [17] is of particular interest due to the number of analyses that involve tryptic peptides derived by hydrolysis of proteins by using the enzyme trypsin. Such peptides incorporate the basic amino acids, arginine or lysine, at the C-terminal position. The gas-phase basicities and proton affinities of the 20 common amino acids have been determined by using a variety of different methods [18-21]. Arginine, which incorporates a guanidino side chain, is by far the most basic, with a proton affinity some $14 \mathrm{kcal} / \mathrm{mol}$ higher than that of histidine, the next most basic amino acid [22]. As a result, the presence of arginine residues in a peptide is expected to exert a strong influence on the location of the proton in peptide $[\mathrm{M}+\mathrm{H}]^{+}$ions.

The development of electrospray ionization [23] has promoted interest in the CAD of multiply charged ions. The issues of charge state and charge location have been studied with respect to the high-energy CAD of multiply charged peptide ions [6]. Electrospray ionization is, however, more commonly coupled to tandem quadrupole mass spectrometers in which the multiply charged peptide precursor ions are subjected to low-energy CAD. Not surprisingly, the product ion spectra of multiply charged species reveal differences in the observed fragmentation patterns in comparison to their singly charged counterparts. This has led to investigations of the role of the ionizing protons and the basic residues in the fragmentation process in terms of their location and interactions within the peptide ion $[4,5,7,8,24]$. In studies of the fragmentation of protonated peptides by surface-induced dissociation, Wysocki and co-workers [25] have rationalized the higher energy requirement for fragmentation of peptides that incorporate a basic residue in terms of the dominance of single stable protonated structure.

Several studies have postulated a correlation between fragmentation patterns and the threedimensional structure of the peptide ion $[8,14,25-29]$. Bursey and co-workers [26], for example, suggested that the prevalence of specific cleavages is associated with the length of the peptide chain, which reflects the influence of internal hydrogen bonding.

Peptide ion fragmentation also has been addressed through molecular modeling [29-31]. Recently, semiempirical [modified neglect of differential overlap
(MNDO)] bond order and diatomic energy calculations were used to evaluate bond strengths and describe the gas-phase fragmentation of peptide ions [24, 32]. The results of these studies indicated that in terms of bond order, the site of protonation has only a local effect, and fragmentation further than three bonds from the charge site could be considered charge-remote. In addition, the MNDO calculations indicated that protonation on the amide nitrogen in the peptide backbone weakens the peptide bond, which facilitates fragmentation, whercas protonation of the amide oxygen makes the amide bond stronger [32].

Our previous studies showed that oxidation of cysteine to cysteic acid in tryptic peptides that contain C-terminal arginines resulted in marked differences in the observed low-energy dissociation spectra [8]. An intraionic acid-base interaction between the cysteic acid and the arginine residue was proposed to account for the differences in CAD of these species. Other studies have shown the detrimental effects of a terminal arginine residue to the low-energy dissociation of singly charged peptide ions [17], in contrast to the high efficiencies observed in the high-energy CAD of the same compounds [33].

The work described here represents a systematic investigation of the effects of charge heterogeneity in the precursor ion population of model peptides in low-energy CAD experiments. The nature and extent of low-energy decompositions of peptides that contain highly basic arginine residues are compared to dissociation of analogous peptides in which highly acidic groups have been incorporated to balance the fixed charge sites, which leaves only the less basic sites available for protonation. In addition, molecular modeling has been utilized to determine preferred low-energy conformational states of these gas-phase peptide ions.

\section{Experimental}

Amino acid residues are designated in this paper by using three letter abbreviations or the standard single letter codes. The cysteic acid residue is denoted by $C^{*}$. The unmodified peptides RLCIFSCFR, RLAIFSCFR, and RLCIFSAFR were synthesized in the School of Biological Sciences, University of Manchester. Carboxypeptidase B was purchased from Sigma Chemical Co. (Poole, UK). All other chemicals used in the derivatization procedures were obtained commercially and were used without further purification.

\section{Carboxypeptidase B Digestion of Peptides}

The synthetic peptides were dissolved $(0.5-1.0 \mathrm{mg})$ in 0.1-M ammonium acetate buffer ( $\mathrm{pH} 8.5$ ). Carboxypeptidase $B$ was added (1:100 enzyme:peptide molar ratio) and allowed to react at $25^{\circ} \mathrm{C}$. The progress of the reaction was monitored by removal of aliquots from the mixture, dilution with $1: 1$ acetonitrile:water $(0.2 \%$ formic acid), and analysis of the timed aliquots by 
electrospray ionization-mass spectrometry (ESI-MS). When the maximum amount of the des-Arg, species had been formed, the reaction was quenched by the addition of $20-\mu \mathrm{L}$ trifluoroacetic acid. The des-Arg ${ }_{9}$ species was then either purified by high-performance liquid chromatography (HPLC) or analyzed directly from the reaction mixture by mass spectrometry.

\section{High-Performance Liquid Chromatography Separation of Peptide Mixtures}

HPLC was performed by using a Waters 600 HPLC pump and controller with a Waters 490 variable wavelength UV detector (Waters Corp., Milford, MA). Separation was achieved using a $C_{18}$ column $(4.6 \times 150$ $\mathrm{mm}$; YMC Corp., Morris Plains, NJ). A linear gradient was formed from $70 \%$ water $(0.1 \%$ trifluoroacetic acid) $30 \%$ acetonitrile $(0.1 \%$ trifluoroacetic acid) to $10 \%$ water $(0.1 \%$ trifluoroacetic acid): $90 \%$ acetonitrile $(0.1 \%$ trifluoroacetic acid) in $30 \mathrm{~min}$. The flow rate was 1.5 $\mathrm{mL} / \mathrm{min}$. The UV detector was set to monitor absorbance at $217 \mathrm{~nm}$. The HPLC fractions were collected and the correct fraction (that contained the des-Arg 9 species) was identified by ESI-MS analysis.

\section{Oxidation of Cysteine Residues to Cysteic Acid [8]}

Performic acid was produced by allowing $1-\mathrm{mL}$ formic acid to react with $0.1 \mathrm{~mL}$ of $30 \% \mathrm{H}_{2} \mathrm{O}_{2}$ for $1 \mathrm{~h}$ at $25^{\circ} \mathrm{C}$. Thirty microliters of performic acid were then added to the peptide solutions [both the unmodified peptide $(0.5 \mathrm{mg})$ dissolved in water and the des- $\mathrm{Arg}_{9}$ analogues dissolved in 0.1-M ammonium acetate buffer].

\section{$N$-Acetylation of RLAIFSC*FR and RLC*IFSAFR [34]}

An equal volume of acetic anhydride was added to a solution of peptide $(200 \mathrm{ng})$ in $200-\mu \mathrm{L}$ water:acetonitrile (1:1) and allowed to react for $10 \mathrm{~min}$ at $37^{\circ} \mathrm{C}$. The reaction mixture was then dried under a stream of nitrogen gas.

\section{Preparation of Des-Arg 1 Peptides}

The peptides were oxidized and $\mathrm{N}$-acetylated by using the procedures described in the preceding text and dried overnight. Then the peptides were redissolved in Tris buffer ( $0.1 \mathrm{M} ; \mathrm{pH}$ 8.5). Trypsin was added (1:50 $w / w$, enzyme:peptide). The progress of the reaction was monitored by mass spectrometry and the reaction was quenched by the addition of formic acid when the concentration of the des- $\operatorname{Arg}_{1}$ species reached a maximum.

\section{Mass Spectrometry}

Singly charged precursor ion species were generated by fast-atom bombardment (FAB) and analyzed by using a VG $7070 Q$ mass spectrometer (VG Organic, Manchester, UK) with the configuration EBqQ (where $\mathrm{E}$ is the electric sector, $\mathrm{B}$ is the magnetic sector, $\mathrm{q}$ is the rf-only quadrupole, and $Q$ is the quadrupole mass filter). The peptide (dissolved in 1:1 methanol:water) was mixed with an equal volume of matrix (1:1 bis-(2hydroxyethyl)-disulfide and thioglycerol) and was bombarded with an $8-\mathrm{keV}$ primary beam of xenon atoms. For tandem mass spectrometry analyses, precursor ions were selected at 1000 mass resolution by using $\mathrm{EB}$ and subjected to CAD in q. The pressure of argon collision gas was sufficient to decrease the precursor ion transmission by $\sim 80 \%$. Product ions were recorded by scanning $Q$, with a resolution set to achieve peak widths of $m / z 1-2$ units. Data were recorded by using a VG $11 / 250$ data system, with acquisition in the "multichannel analyzer" mode; 5-15 scans were accumulated and averaged.

Doubly charged precursor ions were generated by electrospray ionization and analyzed by using a $V G$ Quattro II triple quadrupole mass spectrometer. Peptide samples were dissolved in 1:1 acetonitrile: water ( $0.2 \%$ formic acid) at concentrations of approximately $10 \mathrm{pmol} / \mathrm{L}$. Ten microliters of this solution were then introduced by loop injection into a stream of 1:1 acetonitrile:water flowing at $5 \mu \mathrm{L} / \mathrm{min}$. Ionization was achieved by nebulizer-assisted electrospray where nitrogen was the nebulizing gas and the electrospray needle was held at $3.5 \mathrm{kV}$. Precursor ions were selected at a resolution sufficient to pass the major isotopic variants of the ion of interest into the collision hexapole. Ions were dissociated through collisions with argon, which was present in the collision cell at $5 \times 10^{3}$ mbar. The collision energy was $20-100 \mathrm{eV}$; sperific values are indicated in the Results and Discussion section.

\section{Molecular Modeling}

Peptides were modeled by using the MM2 force field as implemented in MacroModel (Version 3.5x and 4.5) [35]. The modeling program was run on Silicon Graphics (Reading, UK) GTX4, Indigo, and Indigo II workstations. The peptide primary structures were entered with the amino acid residues carrying the charge they would retain in a neutral $\mathrm{pH}$ solution (e.g., the arginine side chain is positively charged). Each structure was taken through two Polak-Riviere conjugate gradient (PRCG) [36] energy minimization routines to find an approximate starting structure. Then the more detailed full-matrix Newton-Raphson (FMNR) [37] energy minimization routine was performed to minimize the structure to the closest local energy minimum. A Monte Carlo conformational search [38, 39] was then performed to locate low-energy structures and to predict the structure of the global energy minimum of each peptide. The Monte Carlo conformational search generates a large number of energetically feasible conformers. The multiconformer minimization [40] was 
used for further minimization of these forms to eliminate structures that were essentially identical due to incomplete convergence. In the 8-9 amino acid peptide structures examined here, this still left approximately 30-100 possible structures within an imposed energy window of $25 \mathrm{~kJ} / \mathrm{mol}$. However, because we are concerned only with broad structural trends, the different minimized structures do not vary significantly in this energy range for our purposes. The lowest energy conformers can be evaluated by examination of the three-dimensional structure, by projection of the number and location of possible hydrogen bond interactions, and by examination of the charge densities around the atoms and the individual bond lengths.

\section{Results and Discussion}

\section{Singly Protonated Precursor Ions}

Singly protonated peptides were generated by fastatom bombardment. The product ion spectrum obtained following collisional activation of singly protonated RLICFSCFR is shown in Figure 1a. The poor yield of structurally diagnostic fragment ions is attributed to the sequestering of the ionizing proton by
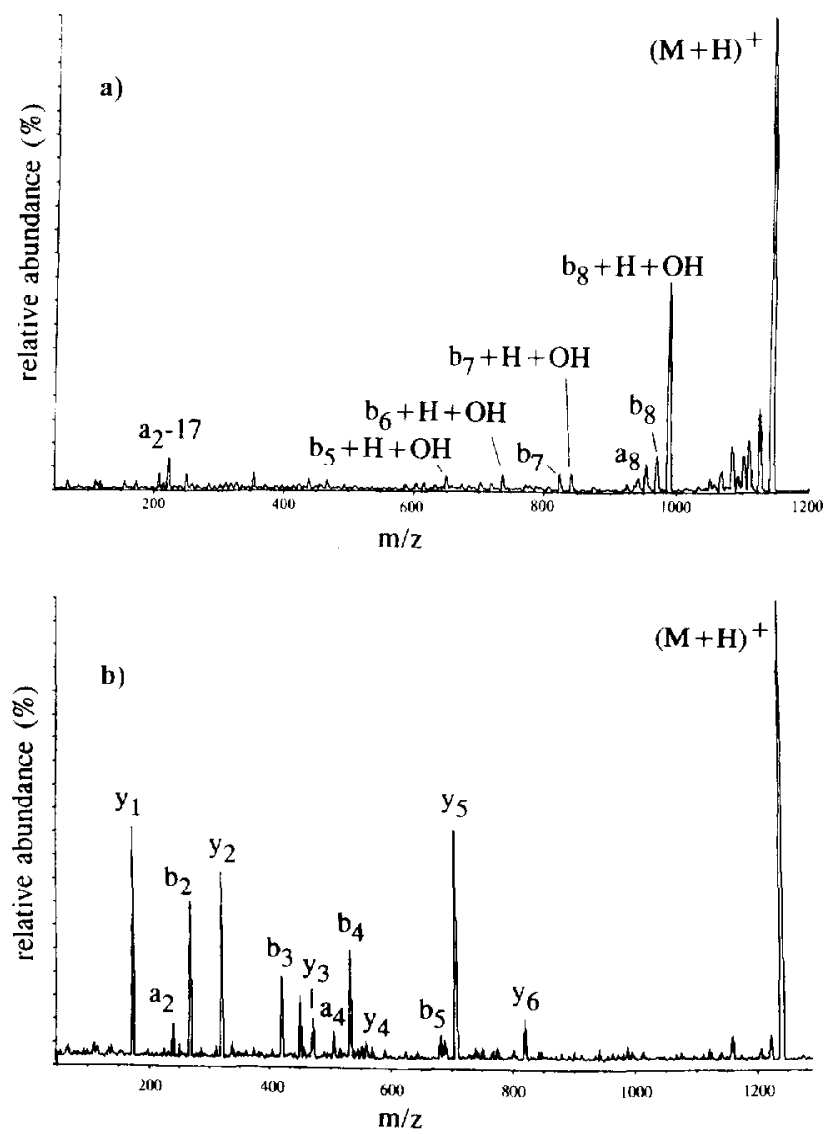

Figure 1. Product ion spectra recorded following low-energy collision-activated dissociation of singly protonated (a) RLCIFSCFR and (b) RLC*IFSC*FR (where C* represents a cysteic acid residue). one of the arginine residues, with a consequent lack of charge-proximal fragmentations of the peptide chain. Arginine is the most basic of all the common amino acid residues [22]; thus the highly basic guanidino groups present in the arginine side chains are strongly favored sites for the ionizing proton. The most prominent fragment ion in this spectrum is attributed to C-terminal rearrangement, which yields $b_{8}+\mathrm{H}+\mathrm{OH}$; lower members of this series of rearrangement ions are present at low abundance. (Peptide fragment nomenclature used throughout this paper is that proposed by Biemann [41], modified from that originally developed by Roepstorff and Fohlman [42]). The mechanism for this rearrangement $[14,15]$ (and for an analogous process in metal-cationized peptides [43-45]) has been studied and is understood in outline; the precise influences of structural features (both proximal and remote to the C-terminus), however, remain to be elucidated.

A markedly different product ion spectrum (Figure $1 b$ ) was obtained from analysis of RLC ${ }^{*} I F S C^{*} F R$, prepared by oxidation of cysteine residues (side chain - $\mathrm{SH}$ ) to cysteic acid (side chain $-\mathrm{SO}_{3} \mathrm{H}$ ) residues (here designated as $\mathrm{C}^{*}$ ). The neutral peptide structure may be envisaged formally as the incorporation of two protonated arginine residues and two deprotonated cysteic acids (with intraionic interactions that mitigate the energy requirement of formal charge separation; see subsequent text). The additional proton that confers a net positive charge is no longer sequestered at a strongly basic site and may be located at one of several positions, which include the amide bonds of the peptide backbone; thus a precursor ion population that is heterogeneous with respect to charge site is generated. Abundant $a-, b$-, and $y$-type sequence ions are observed for this species, and may be considered to result from charge-directed mechanisms $[24,46]$. Both dissociation spectra depicted in Figure 1 were obtained at a collision energy of $20 \mathrm{eV}$; this collision energy resulted in predominantly lower mass fragment ions in the dissociation of the oxidized analog (Figure 1b). Higher collision energies have been shown generally to allow access to more fragmentation channels and facilitate consecutive decompositions [27]. Lower collision energies ( $<20 \mathrm{eV}$; data not shown) favored the higher mass-to-charge ratio fragment ions derived from protonated RLC*IFSC*FR. The improved fragment ion yield observed for the oxidized analog in the present work is consistent with the results obtained by Burlet et al. [8] for synthetic peptides that incorporate single arginine and cysteic acid residues.

The stability of the structure that incorporates protonated arginines and deprotonated cysteic acids may be enhanced by electrostatic interactions between the oppositely charged side chains. Molecular modeling was used to assess the energetically preferred conformations predicted for the gas-phase peptide ions. For molecules of this size, the energy calculations are low level (MM2) and subject to approximations imposed 
by the force field. However, it is also recognized that the mass spectrometric experiment generates precursor ion populations that are energetically quite diverse. Thus, the purpose of modeling these compounds is to provide insight into broad structural features. The MM2 calculated energy-minimized structure for RLC ${ }^{*} I F S C^{*} F R$ is shown in Figure 2. The initial structure was designed to model the neutral compound; the arginine residues are positively charged and the cysteic acids retain a negative charge. It is envisaged that the ionizing protons can reside at a number of points on the peptide backbone. The modeling indicates that the negatively charged cysteic acid groups adopt a position proximal to the positively charged guanidino groups, which opens the structure of this compound (in marked contrast to the model of RLCIFSCFR: data not shown) and gives a clear indication of the significance of electrostatic interactions (treated by MacroModel by using a partial charge model [35]). The distance between the proton on the $\mathrm{N}$-terminal arginine and the negatively charged cysteic acid residue at the 3 position is estimated to be $1.8 \AA$; the distance between the proton on the C-terminal arginine and an oxygen of the other cysteic acid is also $1.8 \AA$. These distances are well within the limits for facile hydrogen bond formation [47].

Rearrangement ions are absent in the product ion spectrum of protonated RLC*IFSC*FR (Figure 1b). This absence may be associated with the highly favorable electrostatic interaction between the C-terminal arginine residue and the cysteic acid at position 7 , which may suppress the adoption of conformations conducive to C-terminal rearrangement. A detailed interpretation of this finding, however, awaits a more com- plete understanding of the effect of structure on the rearrangement process.

\section{Doubly Charged Precursor Ions}

Multiply protonated precursor species were generated by electrospray ionization. In the case of RLCIFSCFR, the mass spectrum showed predominantly $[\mathrm{M}+$ $2 \mathrm{H}]^{2+}$, with a lesser abundance of $[\mathrm{M}+3 \mathrm{H}]^{3+}$; relative proportions depended on the specific electrospray conditions [48]. There was no evidence of the singly charged $\left([\mathrm{M}+\mathrm{H}]^{+}\right)$species. The predominance of the $[\mathrm{M}+\mathrm{H}]^{2+}$ ion may be attributed to protonation of the highly basic arginine guanidino side chains remote from the peptide backbone. The significant yield of $[\mathrm{M}+3 \mathrm{H}]^{3+}$, however, is not surprising. The peptide solutions were prepared in $0.2 \%$ formic acid $(\mathrm{pH} 2.6)$ and the spectra were acquired at relatively low electrospray skimmer voltages that favor the survival of higher charge-state ions $[48,49]$. The third proton must reside at an amide group in the peptide backbone or at the $\mathrm{N}$-terminus. The energy barrier for proton transfer between these sites is low, which results in a precursor ion population that is heterogeneous with respect to site of charge. Accordingly, significant dissociation of the $[\mathrm{M}+3 \mathrm{H}]^{3+}$ species occurred at a collision energy of $20 \mathrm{eV}$, which produced several diagnostic fragment ions (S. G. Summerfield and S. J. Gaskell, in preparation). Significant dissociation of the $[\mathrm{M}+2 \mathrm{H}]^{2+}$ species did not occur until much higher collision energies. Even at $60 \mathrm{eV}$, the efficiency of fragmentation was low and the resulting product ion spectrum was highly complex. This is attributed to the location of sites of protonation remote from the peptide backbone.

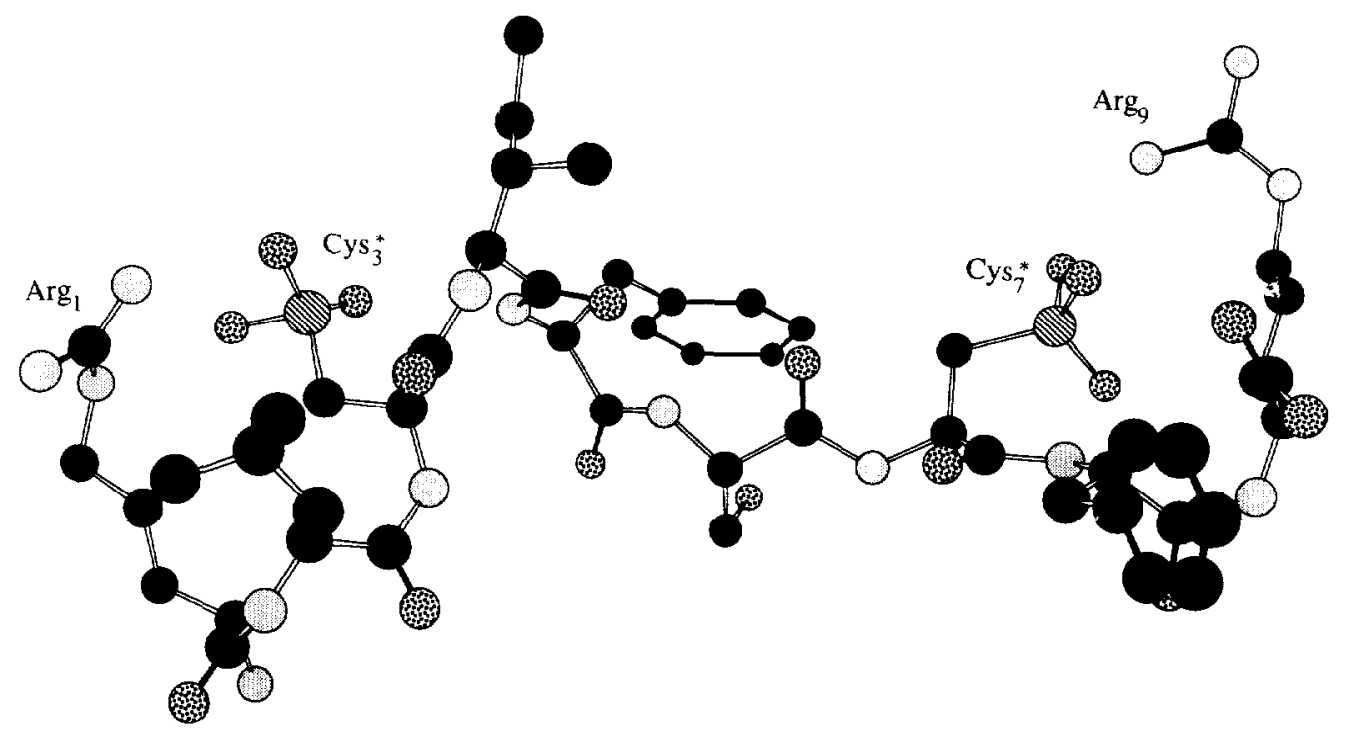

Figure 2. Energy-minimized conformation of RLC*IFSC*FR (where $C^{*}$ represents a cysteic acid

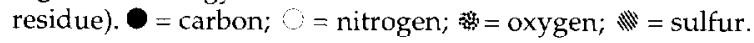


Electrospray ionization of the oxidized peptide RLC* IFSC* FR yielded primarily $[\mathrm{M}+2 \mathrm{H}]^{2+}$ ions with a low abundance of $[\mathrm{M}+\mathrm{H}]^{+}$. This observation is unexpected if the positively charged arginine residues are balanced by the negatively charged cysteic acids. In such a case, the absence of another strongly basic site might favor the production of the singly charged ion. In general, the degree of protonation observed in the electrospray mass spectra of peptide and protein ions is related to the number of basic amino acid residues in the sequence [50] and an additional positive charge that corresponds to the protonation in solution of the N-terminal amine is often seen. In the case of the oxidized peptide RLC*IFSC*FR, the observation of the $[\mathrm{M}+2 \mathrm{H}]^{2+}$ species suggests that the cysteic acid residues are neutral and protonation occurs on the arginine residues. The dramatic differences in the product ion spectra between this compound and its nonoxidized counterpart (discussed subsequently), however, clearly suggest that this distribution of charge is not maintained in the gas-phase structure. The mechanistic aspects of electrospray generation of protonated peptides from solution are still not completely understood and a detailed discussion of these theories is not within the scope of this article. It has been proposed, however, that dramatic changes in $\mathrm{pH}$ occur during the evaporation process [51]. The structure of the solvated peptide ion initially desorbed from acid solution may incorporate protonated arginine residues and neutral cysteic acid residues owing to the highly acidic medium of the desolvating droplet; subsequent desolvation and transfer of ions to the gas phase may then remove structural hindrances, which allows arginine-cysteic acid side-chain interactions and releases protons for location at alternative sites in the peptide structure.

Figure 3 shows a comparison of the dissociation of the $[\mathrm{M}+2 \mathrm{H}]^{2+}$ ions of RLCIFSCFR and RLC*IFSC*FR under the same CAD conditions. In the case of RLCIFSCFR, the ionizing protons are proposed (as previously noted) to remain primarily on the highly basic arginine

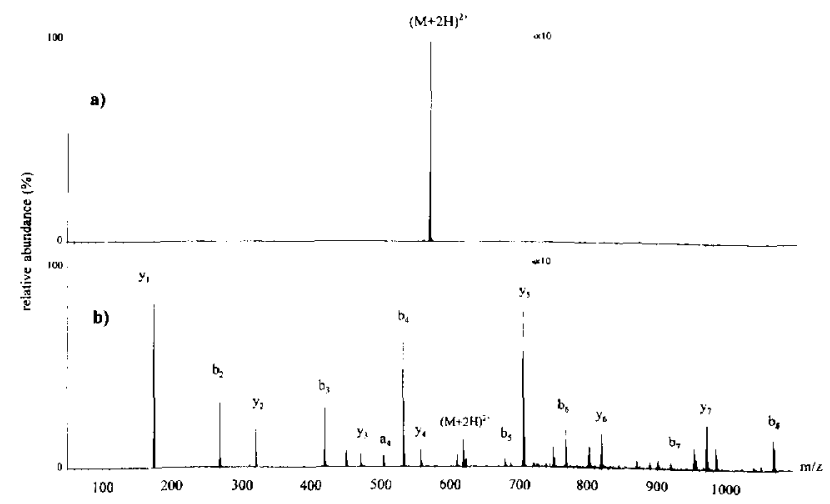

Figure 3. Product ion spectra recorded following low-energy collision-activated dissociation of doubly protonated (a) RLCIFSCFR and (b) RLC*IFSC*FR (where $\mathrm{C}^{*}$ represents a cysteic acid residue). side chains, which results in the observation of inefficient low-energy fragmentation (Figure 3a). In contrast, substantial sequence information is obtained from the dissociation of the bis-cysteic acid precursor ion (Figure $3 \mathrm{~b}$ ). Here the negatively charged cysteic acids balance the protonated arginine side chains, which allows the ionizing protons to reside at a variety of less basic sites. Again, in the absence of other strongly basic sites, the energy barriers between the remaining possible protonated forms are low, and a precursor ion population that is heterogeneous with respect to charge site is generated. A full series of $y$-type and a nearly full series of $b$-type product ions were observed. The $b_{1}$ ion was the only product ion missing from the series, and may reflect a lesser stability than other $b$-type ions that may adopt a protonated oxazolone structure, as proposed by Harrison and co-workers [52].

Electrospray ionization of RLCIFSCF (which lacks the C-terminal R) also can produce a doubly charged precursor ion population that is heterogeneous with respect to charge site. The mass spectrum of this compound again shows $[\mathrm{M}+\mathrm{H}]^{+}$and $[\mathrm{M}+2 \mathrm{H}]^{2+}$. The product ion spectrum of the $[\mathrm{M}+2 \mathrm{H}]^{2+}$ ion is shown in Figure 4. The observation of $b$-type ions (with the exception of $b_{1}$ ) is consistent with a precursor ion population in which one proton remains on the $\mathrm{N}$ terminal arginine, remote from the site of cleavage, while the other proton, which resides along the peptide backbone, is directly involved in charge-proximal fragmentation processes [5].

It is also interesting to note the very low relative abundance of higher members of the $y$-ion series in the product ion spectrum of doubly protonated RLCIFSCF. This appears to be inconsistent with the simple mechanism of charge separation [53] proposed to form complementary $y$ - and $b$-type fragment ion pairs in the dissociation of doubly charged peptide ions. However, equal intensities of the $y$ and $b$ complementary pairs are rarely seen in the dissociation of doubly charged peptide ions. In the case of tryptic peptides, where a strongly basic amino acid residue is at the C-terminus, the $y$-type ions are generally more abundant than the

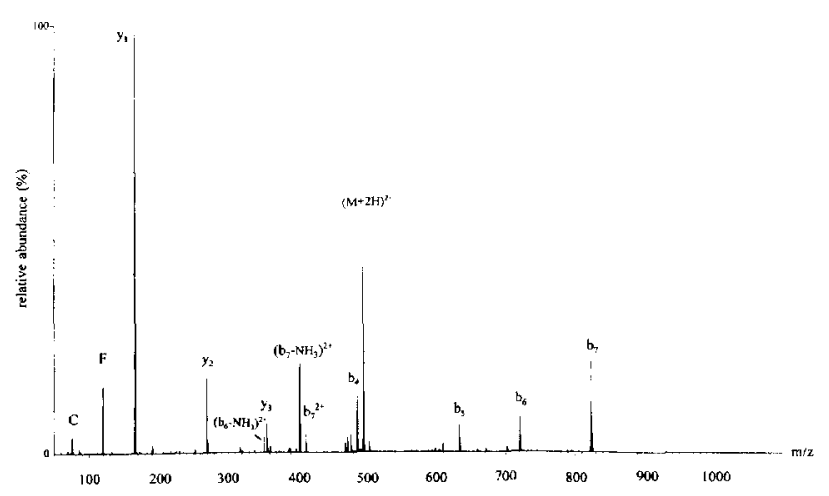

Figure 4. Product ion spectrum recorded following low-energy CAD of doubly protonated RLCIFSCF. 
complementary $b$-ions $[4,54]$. It has been suggested [5] that $y$-ions are inherently more stable than $b$-ions, and are thus more resistant to further decomposition. In the case of RLCIFSCF, the highly basic amino acid residue is at the N-terminus of the peptide, and in this case $b$-ions predominate in the higher mass-to-charge ratio portion of the product ion spectrum. 'Ihese data suggest that the stability of the product ion is not due to its lype $(y$ or $b$ ) but to whether it retains its charge on the side chain of the basic residue, remote from the peptide backbonc, which makes it resistant to further charge-proximal dissociations. The prominence of $y_{2}$ and (particularly) $y_{1}$ ions in the product ion spectrum of doubly protonated RLCIFSCF is attributed to the sequential cleavage of $y$-series ions [16] that are formed as complements to $b$-type ions and are heterogeneous with respect to site of charge. For the example of tryptic peptides, a basic residue is always at the $\mathrm{C}$ terminus; therefore, $y$-type product ions (in which the charge is retained on the C-terminal portion of the compound) dominate the product ion spectrum. $b$-Type ions formed from the dissociation of a tryptic peptide retain the charge on the portion of the structure that lacks strongly basic sites; the ionizing proton in this case resides along the backbone and can promote further charge-proximal fragmentations.

In addition to the dominating series of $b$-ions, the dissociation of doubly protonated RLCIFSCF results in the formation of doubly charged $b_{n}$ and $\left[b_{n}-17\right]$ ions. Doubly charged fragment ions are not detected in the product ion spectrum of RLCIFSCFR and its bis-cysteic acid counterpart. In the case of the des-Arg 9 peptide, the presence of doubly charged fragment ions provides additional evidence that the proton that resides on the N-terminal arginine behaves as a remote spectator to the low-energy fragmentation processes. In the precursor ion population, the proton involved in the charge-proximal fragmentation mechanisms can reside anywhere along the peplide backbone, and when protonation occurs at distances substantially removed from the N-terminus, the precursor ion behaves independently of the fixed N-terminal charge, which results in the formation of doubly charged $b_{6}$ and $b_{7}$ fragment ions. However, when protonation occurs at distances closer than six residues to the fixed charge on the N-terminal arginine, it becomes energetically unfavorable for the two charges to reside on the same fragment, and no further $b_{n}^{2+}$ fragment ions are observed. This again is consistent with previous reports that investigated the dissociation behavior of peptides that contain a precharged derivative [7].

The influence of charge location and the possible influence of electrostatic interactions have been studied further by analysis of the peptides RLAIFSCFR and RLCIFSAFR, together with their oxidized analogs. The sequences differ only in the relative positions of the cysteine and alanine residues at the 3 and 7 positions. The product ion spectra obtained by CAD of the $[\mathrm{M}+2 \mathrm{H}]^{2+}$ ions from the two cysteine-containing peptides reveal, as anticipated from fixed sites of charge, poor fragmentation efficiencies and complicated product ion spectra at high collision energies (data not shown). A collision energy of $60 \mathrm{eV}$ is necessary to obtain sufficient dissociation for a valid comparison of fragment ions. The product ion spectra of these peptide ions are virtually identical in terms of the types of fragments formed and their relative intensities, which indicates no selective behavior due to the different positions of the cysteine and alanine residues.

The $[\mathrm{M}+2 \mathrm{H}]^{2+}$ ions of RLAIFSC*FR and RLC ${ }^{*}$ IFSAFR are envisaged to contain two protonated arginine residues, a deprotonated cysteic acid, and a single variable site of protonation. The product ion spectra show marked differences (Figure 5). Both species fragment efficiently at $30-\mathrm{eV}$ collision energy; once again, this is attributed to precursor ion populations that are heterogeneous with respect to charge site. There are, however, striking differences between the appearance of the product ion spectra for the two doubly protonated peptides. The product ion spectrum of RLAllSC*FR $[\mathrm{M}+2 \mathrm{H}]^{2+}$ ions is dominated by $y_{1}$ and $y_{2}$ fragments; the structures of these fragment ions are predicted to incorporate a fixed charge and will therefore be relatively stable to further fragmentation. In contrast, higher members of the singly charged $y$-series, which incorporate a cysteic acid residue, will incorporate a mobile site of charge and will therefore be prone to charge-directed fragmentation, which yields lower members of the $y$ series.

Similar principles may be applied to the interpretation of the product ion spectrum of RLC ${ }^{*}$ IFSAFR $[\mathrm{M}+2 \mathrm{H}]^{2+}$ ions. In this instance, members of the $y$ series to $y_{6}$ incorporate solely sites of charge fixed on the C-terminal arginine guanidino group; they are accordingly relatively stable and are observed with significant relative abundance. The $b$-type product ion series is also observed, with a particularly prominent $b_{2}$. Combination of the present ideas with those of Harrison and co-workers [52] suggests that the $b_{2}$ ion possesses a protonated oxazolone structure with a particular stability attributable to the sequestering of the ionizing proton by the guanidino side chain.

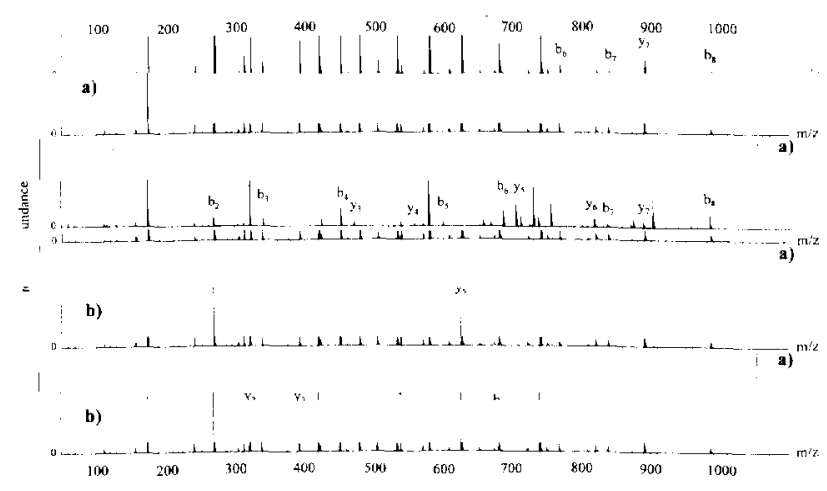

Figure 5. Product ion spectra recorded following low-energy CAD of doubly prolonated (a) RLAIFSC ${ }^{*}$ FR and (b) RLC*IFSAFR (where $C^{*}$ represents a cysteic acid residue). 
The influence of the cysteic acid position is apparent also in the energy-minimized structures of the two analogs. RLAIFSC*FR and RLC ${ }^{*} I F S A F R$. Interestingly, the energy-minimized structure of RLAIFSC*FR (Figure 6a) indicates a close association between the cysteic acid and the $\mathrm{N}$-terminal arginine, and no interaction with the $\mathrm{C}$-terminal arginine. The distance between the proton on the $\mathrm{N}$-terminal arginine and the acidic oxygen on the cysteic acid is $1.8 \AA$. In this case, a stabilizing interaction between the cysteic acid and the
$\mathrm{N}$-terminal arginine is favored; this reduces the probability that the ionizing proton resides on the $\mathrm{N}$ terminal guanidino group. This reduction may contribute to favor the C-terminal fragment ions. Further study is required, however, to enable a full assessment of the influence of conformation on fragmentation pathways. Molecular modeling studies indicate that the energy-minimized conformation of RLC*IFSAFR involves not only a close interaction between the cysteic acid and $\mathrm{N}$-terminal arginine, but also a close

(a)

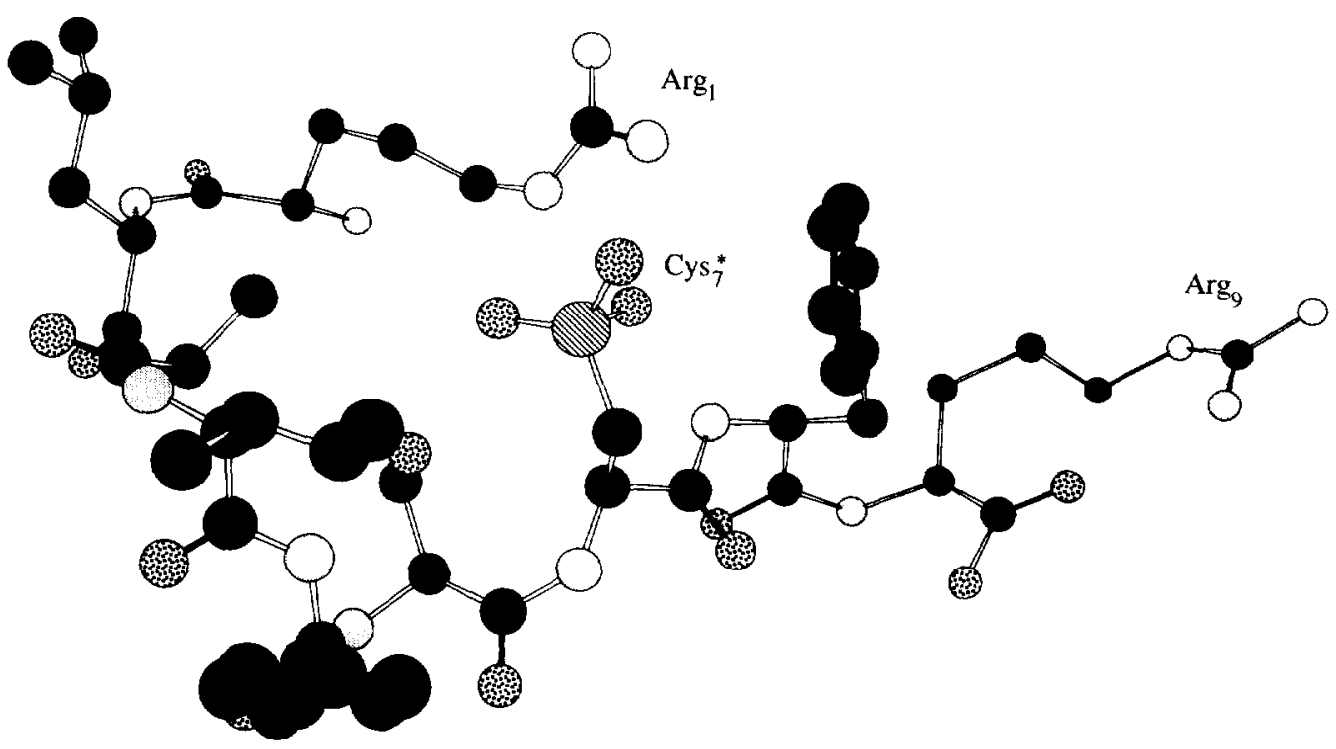

(b)

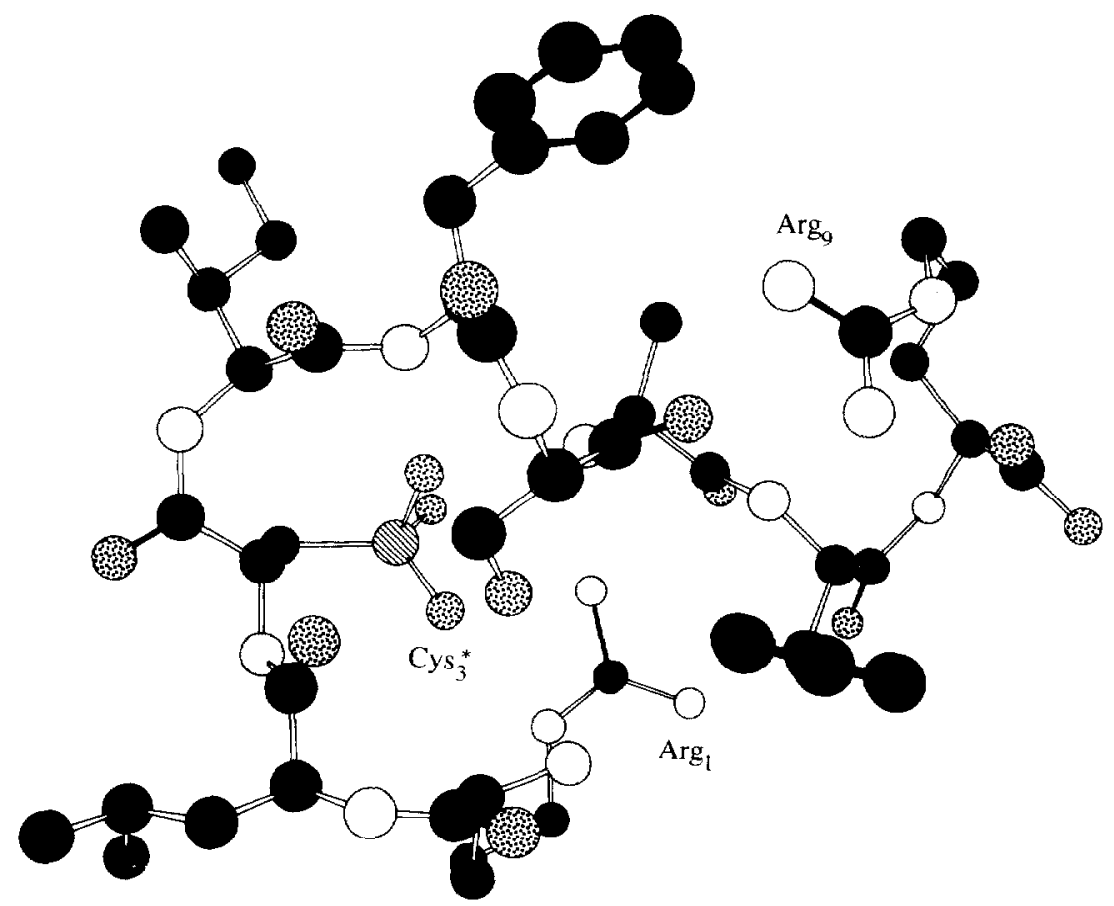

Figure 6. Energy-minimized conformation of $(a)$ RLAIFSC*FR and $(b)$ RLC*IFSAFR (where C*

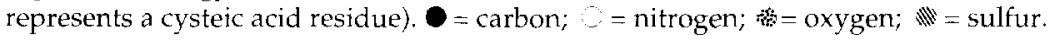


interaction between the cysteic acid and the serine side chain (Figure 6b). Here the distance between the proton on the $\mathrm{N}$-terminal arginine and the acidic oxygen on the cysteic acid is $1.8 \AA$ and the distance between the hydrogen on the serine residue and the acidic cysteic acid oxygen is $1.7 \AA$.

The des-Arg 1 analogs of these oxidized peptides also have been analyzed. Figure 7 shows the product ion spectra of the $[\mathrm{M}+2 \mathrm{H}]^{2+}$ ions of LAIFSC"FR and LC*IFSAFR. The data are qualitatively similar to those recorded for the equivalent ions that incorporate an $\mathrm{N}$-terminal arginine. Thus, the spectrum of LAIFSC ${ }^{*} \mathrm{FR}$ is dominated by lower members of the $y$ series of product ions. Higher members of the series contain both arginine and cysteic acid residues, and the location of the proton that confers a net positive charge is thus variable; the ions therefore readily fragment to give lower members of the series. In contrast, $y$-series ions ( $y_{6}$ and lower) derived from doubly protonated LC ${ }^{*}$ IFSAFR are expected to incorporate a fixed site of charge (the arginine side chain) and are accordingly relatively stable to further tragmentation. Molecular modeling of these two structures (which incorporate protunated argine side chains and deprotonated cysteic acids) also was performed. The lowest energy conformation of LAIFSC*FR involves an arginine-cysteic acid interaction, but, interestingly, no such interaction is evident for LC*IFSAFR.

\section{Conclusions}

The peptides investigated here were synthesized and modified to address the specific question of the role of site(s) of charge in determination of the extent and nature of low-energy fragmentations of singly and multiply charged peptide ions in the gas phase. The presence of highly basic arginine residues severely attenuates the fragmentation efficiency of singly charged ions following low-energy collisional activation by sequestering the ionizing proton at a site removed from the backbone of the peptide ion. Efficient fragmentation processes in low-energy $\mathrm{CAD}$ are dic-

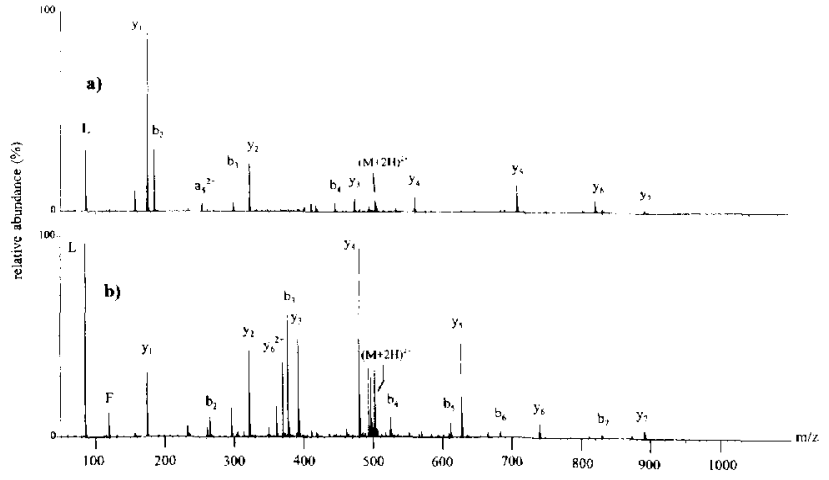

Figure 7. Product ion spectra recorded following low-energy CAD of doubly protonated (a) LAIFSC*FR and (b) LC* IFSAFR (where $C^{*}$ represents a cysteic acid residue). tated by charge-proximal mechanisms, and a precursor ion population that is heterogeneous with respect to charge site appears to be essential for efficient fragmentation via multiple structurally diagnostic pathways.

If only one highly basic residue is present in the peptide, a much higher fragmentation efficiency is observed in the dissociation of the doubly protonated precursor than of the singly protonated analog. The majority of the precursor ion population of the doubly charged species will still carry onle proton on the basic side chain, but the second ionizing proton can reside at any other basic site along the peptide backbone, which facilitates charge-proximal fragmentations. In addition, the presence of a basic amino acid allows predictions to be made about the stabilities of product ions. In the dissociation of doubly charged precursors with a basic residue at the $\mathrm{N}$-terminus, a dominating series of $b$ type ions is observed, whereas in the case of a peptide with a C-terminal basic residue (as in tryptic peptides) the dominating series consists of $y$-type ions. This is not primarily due to the inherent stability of one type of fragment ion over the other, but to the fact that the retained proton is remote from the peptide backbone, which inhibits further charge-proximal fragmentations.

The charge on a prolonated arginine side chain can be counterbalanced by the incorporation of a strongly acidic group (such as cysteic acid) into the peptide sequence. Molecular modeling suggests that intraionic interactions reduce the energy requirement of charge separation implicit in the formal zwitterionic structure. A proton that confers a net positive charge is then able to reside at alternative sites on the peptide backbone, which creates a precursor population heterogeneous with respect to site of charge and promotes highly efficient fragmentation with the formation of many characteristic sequence ions.

\section{Acknowledgments}

This work was supported by the U.K. Engineering and Physical Sciences Research Council (grant number GR/K18658) and, in part, by the British Mass Spectrometry Society. The authors also thank Mark Bolgar for valuable discussions.

\section{References}

1. Johnson, R. S.; Martin, S. A.; Biemann, K. Int. J. Mass Spectrom. Ion Processes 1988, 86, 137-154.

2. Johnson, R. S.; Martin, S. A.; Bicmann, K.; Stults, J. T.; Watson, J. T. Anal. Chem. 1987, 59, 2621-2625.

3. Kenny, P. T. M.; Nomoto, K.; Orlando, R. Rapid Commun. Mass Spectrom. 1992, 6, 95-97.

4. Tang, X.-J.; Boyd, R. K. Rapid Commun. Mass Spectrom. 1992, $6,651-657$.

5. Tang, X.-J.; Thibault, P.; Boyd, R. K. Anal. Chem. 1993, 65, $2824-2834$

6. Downard, K. M.; Biemann, K. I. Am. Soc. Mass Spectrom. 1994, 5, 966-975.

7. Burlet, O.; Orkiszewski, R. S.; Ballard, K. D.; Gaskell, S. J. Rapid Commun. Mass Spectrom. 1992, 6, 658-662. 
8. Burlet, O.; Yang, C.-Y.; Gaskell, S. J. J. Am. Soc. Mass Spectrom. 1992, 3, 337-344.

9. Jensen, N. J.; Tomer, K. B.; Gross, M. L. I. Am. Chem. Soc. $1985,107,1863-1868$.

10. Adams, J.; Gross, M. L. I. Am. Chem. Soc. 1986, 108, 6915-6921.

11. Wagner, D. S.; Salari, A.; Gage, D. A.; Leykam, J.; Fetter, J.; Hollingsworth, R.; Watson, J. T. Biol. Mass Spectrom. 1991, 20, 419-425.

12. Watson, J. T.; Wagner, D. S.; Chang, Y.-S.; Strahler, J.; Hanash, S.; Gage, D. A. Int. I. Mass Spectrom. Ion Processes 1991, 111, 191.

13. Zaia, J.; Biemann, K. J. Am. Soc. Mass Spectrom. 1995, 6, $428-436$.

14. Thorne, G. C.; Ballard, K. D.; Gaskcll, S. J. I. Am. Soc. Mass Spectrom. 1990, 1, 249-257.

15. Ballard, K. D.; Gaskell, S. J. J. An. Chem. Soc. 1992, 114, 64-71.

16. Ballard, K. D.; Gaskell, S. J. Int. J. Mass Spectrom. Ion Processes 1991, 111, 173-189.

17. Poulter, L.; Taylor, L. C. E. Int I. Mass Spectrom. Ion Processes 1989, 91, 183-197.

18. Meot-ner (Mautner), M.; Hunter, E. P.; Field, F. H. I. Am. Che'n. Soc. 1979, 101, 686-689.

19. Locke, M. J.; Mclver, R. T. I. Am. Clkm. Soc. 1983, 105, $4226-4232$.

20. Bojesen, G. J. Am. Chem. Soc. 1987, 109, 5558-5560.

21. Gorman, G. S.; Speir, J. P.; Turner, C. A.; Amster, I. J. 1. Am. Chem. Soc. 1992, 114, 3986-3988.

22. Wu Z.; Fenselau, C. Rapid Commum. Mass Spectronn. 1992, 6. 403-405.

23. Yamashita, M.; Fenn, J. I. Phys. Chom. 1988, 88, 4451-4459.

24. McCormack, A. L.; Somogyi, A.; Dongre, A. R.; Wysocki, V. H. Anal. Cltem. 1993, 65, 2859-2872.

25. Jones, J. L.; Dongré, A. R.; Somogyi, A.; Wysocki, V. H. I. An. Soc. 1994, 116, 8368-8369.

26. Yeh, R. W.; Grimley, J. M.; Bursey, M. M. Biol. Mass Spectrom. 1991, 20, 443-450.

27. Morgan, D. G.; Bursey, M. M. Biol. Mass Spectrom. 1993, 22, $502-510$.

28. Schwarte, B. L.; McClain, R. D.; Erickson, B. W.; Bursey, M. M. Rapid Commun. Mass Spritrom. 1993, 7, 339-342.

29. Gooch, E. E.; Holden, C. R.; Bursey, M. M. Biol. Mass Spectrom. 1993, 22, 143-144.

30. Leary, J. A.; Zhou, Z.; Ogden, S. A.; Williams, T. D. I. Am. Soc. Mass Spectronl. 1990, 1, 473-480.
31. Teesch, L. M.; Adams, J. J. Am. Chem. Soc. 1991, 113, 812-820.

32. Somogyi, A.; Wysocki, V. H.; Mayer, I J. Am. Soc. Mass Spectrom. 1994, 5, 704-717.

33. Bean, M. F.; Carr, S. A.; Thorne, G. C.; Reilly, M. H.; Gaskell S. J. Anal. Chem. 1991, 63, 1473-1481.

34. Gaskell, S. J.; Reilly, M. H. Rapid Commun. Mass Spectrom. 1988, 2, 188-191.

35. Mohamadi, F.; Richards, N. G. J.; Guida, W. C.; Liskamp, R.; Lipton, M.; Caufield, C.; Chang, G.; Hendrickson, T.; Still, W. C. J. Comput. Chom. 1990, 11, 440-467.

36. Polak, E.; Ribiere, G. Reoue Française Informat. Recherche Operationelle 1969, 16, 35.

37. Burkert, U.; Allinger, N. L. In Molecular Mechanics; ACS Monograph 177; American Chemical Society: New York, 1982; p. 67.

38. Chang, G.; Guida, W. C.; Still, W. C. J. Am. Chem. Soc. 1989, $111,4379-4386$.

39. Goodman, J. M.; Still, W. C. J. Comput. Chem. 1991, 12, $1110-1117$

40. Lipton, M.; Still, W. C. J. Comptu. Chem. 1988, 9, 343-355.

41. Biemann, K. Biomed. Environ. Mass Spectrom. 1988, 16, 99-111.

42. Roepstorff, P.; Fohlman, J. Biomed. Mass Spectrom. 1984, 11, 601.

43. Grese, R. P.; Cerny, R. L.; Gross, M. L. I. Am. Chem. Soc, 1989, $111,2835-2842$.

44. Renner, D.; Spiteller, G. Biomed. Environ. Mass Spectrom. 1988, 15, 75-77.

45. Tang, K.; Ens, W.; Standing, K. G.; Westmore, J. B. Anal. Chem. 1988, 60, 1791-1799.

46. Hunt, D. F.; Yates, J. R., III; Shabanowitz, J.; Winston, S.; Hauer, C. R. Proc. Natl. Acad. Sci. USA 1986, 83, 6233-6237.

47. Croon-Batenburg, L. M. J.; Kanters, J. A. I. Mol. Struct. 1983 , $105,417-425$.

48. Ashton, D. S.; Beddell, C. R.; Cooper, D. J.; Green, B. N.; Oliver, R. W. A. Org. Mass Spectrom. 1993, 28, 721-728.

49. Smith, R. D.; Loo, J. A.; Loo, R. R.; Busman, M.; Ldseth, H. R. Mass Spectrom. Rom. 1991, 10, 359-452.

50. Covey, T. R.; Bonner, R. F.; Shushan, B. I.; Henion, J. Rapid Commun. Mass Spectrom. 1988, 2, 249-256.

51. Kebarle, P.; Tang, L. Anal. Chcm. 1993, 65, 972A-986A

52. Yalcin, T.; Khouw, C.; Csizmadia, I. G.; Peterson, M. R.; Harrison, A. G. J. Am. Soc. Mass Spectrom. 1995, 6, 1165-1174.

53. Vekey, K.; Candido, M.; Traldi, P. Rapid Commun. Mass Spectrom. 1990, 4, 74-76.

54. Barinaga, C. J.; Edmonds, C. G.; Ldseth, H. R.; Smith, R. D. Rapid Commun. Mass Spectrom. 1989, 3, 160-164. 